\title{
Deciphering extreme mineral records; microstructural phase heritage of shocked materials
}

Timmons Erickson ${ }^{1}$, Nicholas Timms ${ }^{2}$, Aaron Cavosie ${ }^{2}$, Mark Pearce $^{3}$ and Cyril Cayron ${ }^{4}$

${ }^{1}$ Jacobs-JETS, NASA JSC, Houston, Texas, United States, ${ }^{2}$ Curtin University, Perth, Western Australia, Australia, ${ }^{3}$ CSIRO, Kensington, Western Australia, Australia, ${ }^{4}$ École Polytechnique Fédérale de Lausanne (EPFL), Laussane, Neuchatel, Switzerland

High-pressure minerals such as coesite, stishovite, and reidite are often used as indicators of shock metamorphism. However, high-pressure and high-temperature phases are metastable at ambient conditions and, therefore, often revert to a more energetically favorable phase. During solid-state transformations, the crystallographic orientations of the stable polymorph are controlled by the transformation pathway from the parent.

Microstructural orientation analysis using electron backscatter diffraction (EBSD) of the stable phase can reveal systematic intercrystalline orientation relationships (OR) diagnostic of solid-state transformations from these high-pressure or high-temperature polymorph phases (Cayron et al., 2006). Knowledge of polymorph stability fields for a given system can thus be used to infer minimum shock $\mathrm{P}$ and/or $\mathrm{T}$ conditions that rocks have experienced, which are otherwise unavailable using traditional thermobarometers such as element partition coefficients. Using orientation relationships to infer the former presence of mineral phases has been termed microstructural "phase heritage", and has successfully been used to probe for evidence of extreme pressures and temperatures resulting from hypervelocity impacts.

The reconstruction of polymorphs of $\mathrm{ZrSiO}_{4}$ (zircon, reidite) and $\mathrm{ZrO}_{2}$ (baddeleyite) have further elucidated the behavior of these phases under hypervelocity impact conditions (Timms et al., 2017a; White et al., 2018), and OR analysis of shocked monazite has identified a previously unrecognized tetragonal high-P polymorph (Erickson et al., 2019). Zircon will convert to the low tetragonal polymorph reidite at shock stresses above $\sim 21 \mathrm{GPa}$. However, upon decompression at temperatures above $1200{ }^{\circ} \mathrm{C}$ reidite will revert to zircon (Kusaba et al., 1985). Recrystallized zircon neoblasts encased in impact melt often show systematic misorientation relationships of $90^{\circ}$ about $<110>$ indicative of reversion from the reidite (Fig. 1 ), and preserving cryptic evidence of the high-P history that is often erased by the post shock thermal spike (Cavosie et al., 2016).

Microstructural OR analysis of a dissociated zircon corona composed of baddeleyite (monoclinic- $\mathrm{ZrO}_{2}$ ) has identified the former presence of cubic zirconia within impact melt glass from the Mistastin Lake impact structure, Labrador, $\mathrm{CA}$. Based on stability fields in the $\mathrm{ZrO}_{2}-\mathrm{SiO}_{2}$ binary phase diagram, cubic zirconia records thermal conditions in excess of $2370{ }^{\circ} \mathrm{C}$ at ambient $\mathrm{P}$, indicating that the Mistastin impact melt is the hottest rock identified on Earth's surface (Timms et al., 2017b).

Shock-deformed monazite (monoclinic La,Ce,ThPO4) containing lamellae comprised of interlocking laths has been identified from the Haughton Dome impact structure, Nunavut, Canada and Nördlinger-Ries Crater, southern Germany. The lath-structured lamellae are composed of four systematic orientation variants, which OR analyses indicate originate from a tetragonal parent whereby the [010]monoclinic aligns with either [100] or [010]tetragonal (Erickson et al., 2019). 
These results highlight utility of microstructural phase heritage analyses for the identification of unstable high-P or high-T polymorphs that uniquely record the extremely transient shock conditions produced by hypervelocity impacts.
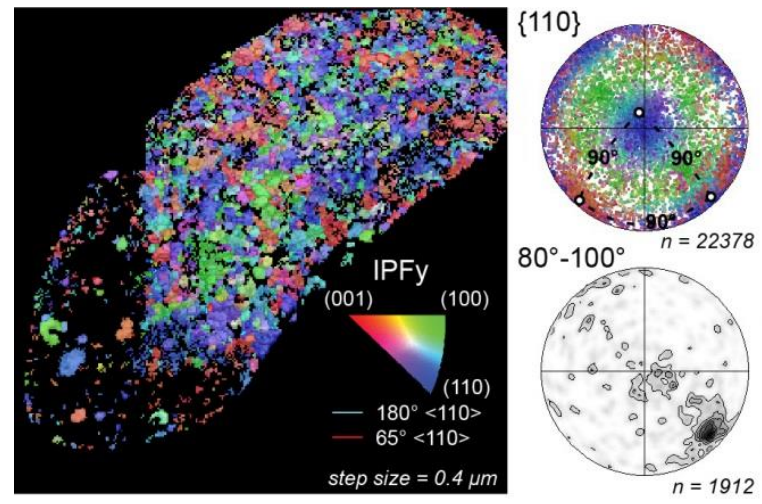

Figure 1. Shock recrystallized zircon from the Yarrabubba impact structure displaying systematic misorientation $90^{\circ}$ about indicative of reversion from the high-P polymorph reidite.

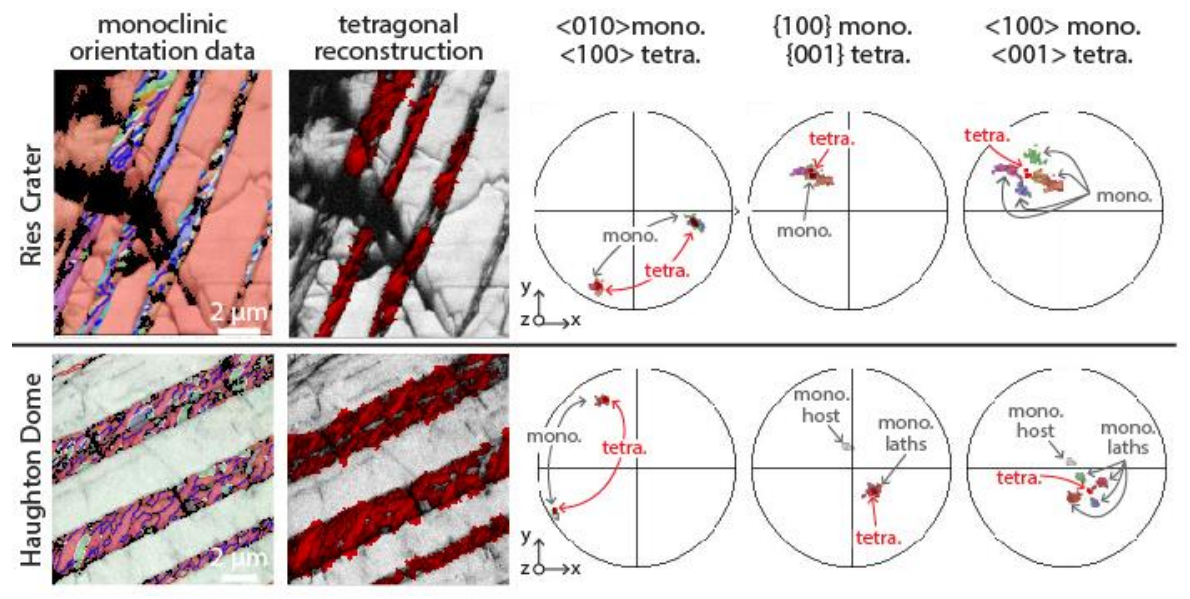

Figure 2. Shocked monazite from the Ries and Haughton impact structures displaying lath-structured lamellae composed of four crystallographic orientations indicative of reversion from a cryptic high-P tetragonal polymorph.

\section{References}

Cavosie, A. J., Timms, N. E., Erickson, T. M., Hagerty, J. J., and Hörz, F., 2016, Transformations to granular zircon revealed: Twinning, reidite, and $\mathrm{ZrO} 2$ in shocked zircon from Meteor Crater (Arizona, USA). Geology, 44, 703-706.

Cayron, C., Artaud, B., and Briottet, L., 2006, Reconstruction of parent grains from EBSD data: Materials Characterization, 57, 386-401

Erickson, T. M., Timms, N. E., Pearce, M. A., Cayron, C., Deutsch, A., Keller, L. P., and Kring, D. A., 2019, Shock-produced high-pressure (La, Ce, Th) PO4 polymorph revealed by microstructural phase heritage of monazite. Geology 47, 504-508.

Kusaba, K., Syono, Y., Kikuchi, M., and Fukuoka, K., 1985, Shock behavior of zircon: Phase transition to scheelite structure and decomposition. Earth and Planetary Science Letters, 72, 433-439. 
Timms, N. E., Erickson, T. M., Pearce, M. A., Cavosie, A. J., Schmieder, M., Tohver, E., Reddy, S. M., Zanetti, M. R., Nemchin, A. A., and Wittmann, A., 2017a, A pressure-temperature phase diagram for zircon at extreme conditions: Earth-Science Reviews, 165, 185-202.

Timms, N. E., Erickson, T. M., Zanetti, M. R., Pearce, M. A., Cayron, C., Cavosie, A. J., Reddy, S. M., Wittmann, A., and Carpenter, P. K., 2017b, Cubic zirconia in $>2370{ }^{\circ} \mathrm{C}$ impact melt records Earth's hottest crust: Earth and Planetary Science Letters, 477, 52-58.

White, L. F., Darling, J. R., Moser, D. E., Cayron, C., Barker, I., Dunlop, J., and Tait, K. T., 2018, Baddeleyite as a widespread and sensitive indicator of meteorite bombardment in planetary crusts: Geology, v. 46, no. 8, p. 719-722. 